\title{
Analysis of Migration Processes and Recommendations on Regulation of Internal Migration from Southern to Northern Regions of Kazakhstan
}

\author{
Kairat Bodaukhan ${ }^{+*}$ Aruzhan Jussibaliyeva, ${ }^{\ddagger}$ Raushan Mussina, ${ }^{\neq}$Darima Zhenskhan,,${ }^{\ddagger}$ Zhanerke
} Kochiigit ${ }^{\top}$ and Indira Amerkhanovaí

\begin{abstract}
Migration data is a useful tool for creating a single internal economic space that is harmoniously integrated with the global economy by helping to create conditions for the growth of economic and business activity of economic entities. Migration processes, primarily labour migration, are among the significant factors affecting the socio-economic situation both in the country as a whole and in its regions. This study discusses the following issues: state regulation of migration processes; statistical analysis and interpretation of data on internal migration from labour-surplus to labourdeficient regions. In order to achieve the objectives, the study uses statistical data on the interregional migration in the country; World Health Organization's (WHO's) indicators of social welfare; International Labour Organization's (ILO's) unemployment assessment; the dynamics of demographic processes in society. Following the findings, the study presents recommendations on the regulation of internal migration from southern to northern regions of Kazakhstan. Thus, the research results can be implemented when developing regulatory legal acts, migration management programmes, etc. The findings of this study can be used as a basis for assessing the dynamics of the social well-being of migrants in Central Asia.
\end{abstract}

Keywords: Migration Processes; Population Resettlement; State Regulation of Migration, Kazakhstan

\footnotetext{
${ }^{+}$S. Seifullin Kazakh AgroTechnical University, Kazakhstan

*Corresponding Author, Email: bodaukhank@gmail.com; kairat_2208@mail.ru

${ }^{\sharp}$ S. Seifullin Kazakh AgroTechnical University, Kazakhstan

iNazarbayev University, Nur Sultan, Kazakhstan

'́Kazakh Humanitarian Law Innovative University, Semey, Kazakhstan

(C) 2020 Bodaukhan et al. This is an Open Access article distributed under the terms of the Creative Commons Attribution License (http://creativecommons.org/licenses/by/2.0), which permits unrestricted use, distribution, and reproduction in any medium, provided the original work is properly cited.
} 


\section{Introduction}

Migration processes have a significant impact on labour markets and labour force. Migration not only affects the socio-economic situation in the regions but also facilitates the shaping of a healthy well-functioning society and permits the optimal allocation of labour resources within the country. Countries create unique systems to regulate labour migration at national and global levels in order to reduce the negative consequences of labour shifts and to enhance their positive implications (Shakhaman, Taskuzhina, \& Kudritskaya, 2018).

A study of the current migration situation in Central Asia shows the following tendencies:

- resettlement to regions of higher economic development potential;

- active measures to relocate citizens from labour-surplus regions of the country to labour-deficient regions (Bodauhan \& Jussibaliyeva, 2018a).

These trends are especially pronounced in countries with transition economies. Economic transformation leads to changes in social institutions, completely rebuilding social life. Among post-Soviet states, Kazakhstan is the most prominent examples of internal migration. Nowadays, Kazakhstan is forced to "distribute" human capital across the country in order to disperse the concentration of labour that is sensitive to changes in production factors (Adams, 2018).

In case of successful "distribution", state receives employed population, income to the budget, improved quality of life and, as a result, sustainable development of the economic system. However, a synergistic result is possible only in case of the following:

- a useful model of managing migration processes;

- taking into account geopolitical and socio-demographic factors;

- adapting the international experience to the specific economic system.
Thus, an interim analysis of the migration situation in the region and its prospects (on the example of Kazakhstan) will allow identifying the following:

- key measures in solving migration problems;

- the most effective public policy instruments to regulate migration processes.

This study consists of five main sections. The "introduction section presents an analytical review of the migration situation in Central Asia. The "methods" section describes procedures of the multicomponent analysis of internal migration's socio-economic impact on demographic and macroeconomic processes in Kazakhstan. This follows the "results section", which shows an analysis of internal migration from one region to another. The "discussion" section allows evaluating alternative approaches to internal migration regulation and formulates suggestions for improving the existing mechanism. The "conclusion" section outlines the analytical quintessence of the study, which can become a valuable basis for further developments in the field of internal migration.

\section{Methods}

In this study, the authors use the method of macroeconomic analysis, alongside the statistical, graphical method of economic research. The focus of the work is on the following issues:

- quantitative analysis of statistical data on the situation of inter-regional migration in Kazakhstan;

- identification of socio-economic problems of resettlement from laboursurplus to labour-deficient regions of Kazakhstan, using the indicators of social well-being of WHO ;

- unemployment assessment according to the ILO methodology;

- calculating the dynamics of demographic processes in society;

- identifying dependencies between external and internal migrations. 


\section{Results}

The principal purpose of this research was to analyse the migration processes and recommendations on regulation of internal migration from Southern to Northern Regions of Kazakhstan. The findings unravel that the general migration trend of Kazakhstan is the increase in the flow of external migration indicating that $44 \%$ of those leaving Kazakhstan for permanent residence in another country are young people aged between 15 to 34 . In the first quarter of 2019, 8.4 thousand people left Kazakhstan (that is, $22 \%$ more compared to the same period of 2018). At the same time, 3.2 thousand people arrived - only $8.4 \%$ more than in the previous year. This trend increased the adverse balance of external migration from 3.4 thousand to 5.2 thousand people. In addition, this trend negatively affects the labour market and reduces the opportunities for economic development (Workforce Development Centre, 2019).

Compared to 01 July 2018, the population in 2019 increased by 235.5 thousand people or $1.3 \%$. As can be seen from Figure 1, over the period under review, the most significant total increase is observed in three regions of the country: Nur-Sultan (56.1 thousand people), Almaty (48.6 thousand people) and Turkestan region (42.6 thousand people).

At the same time, the population continues to decline mainly in the northern regions of Kazakhstan (as of 01 July 2019). The amount of migration in Karaganda region was 735 over six months. In other regions, it was higher - ranging from 808 in Pavlodar region to more than 2,000 in Kostanay (2,120), East Kazakhstan (2 408), and North Kazakhstan (2688) regions.

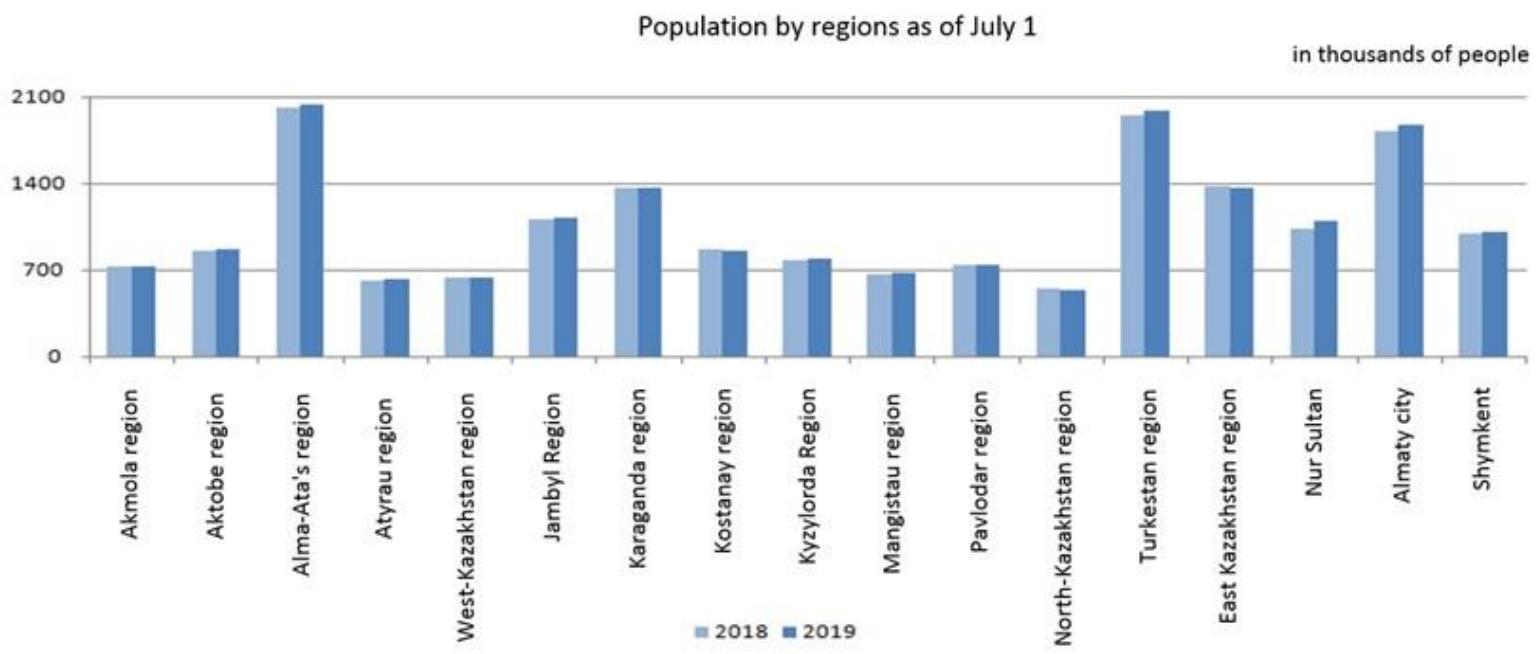

Figure 1: Population by Regions of Kazakhstan

Source: Data of the Committee on Statistics of the Ministry of National Economy of the Republic of Kazakhstan (2019)

According to the Committee on Statistics of the Republic of Kazakhstan (2019), the population of the country as of 01 July 2019, stood at 18,507.9 thousand, including urban population $-10,781.6$ thousand (58.3\%) and rural $-7,726.3$ thousand (41.7\%).

The population of the country as of 01 From the indicators on internal and external September 2019, was 18,547.5 thousand, migration illustrated in Table 1, it is apparent including urban - 10,816.1 thousand (58.3\%), rural $-7,731.4$ thousand (41.7\%). Compared to 1 September 2018, the population increased by 235.7 thousand or $1.3 \%$ (Committee on Statistics of the Ministry of National Economy of the Republic of Kazakhstan, 2019). 
that when compared between January-June arrivals in Kazakhstan decreased by $11.3 \%$, while 2019 with January-June 2018, the number of the number of departures increased by $16.9 \%$.

\begin{tabular}{|c|c|c|c|c|c|}
\hline \multirow[t]{2}{*}{ Time Period } & \multirow{2}{*}{$\begin{array}{l}\text { External } \\
\text { migration }\end{array}$} & \multicolumn{2}{|l|}{ Including: } & \multirow{2}{*}{$\begin{array}{l}\text { Internal } \\
\text { migration }\end{array}$} & \multirow[t]{2}{*}{ Total } \\
\hline & & $\begin{array}{l}\text { CIS } \\
\text { countries }\end{array}$ & $\begin{array}{l}\text { Other } \\
\text { countries }\end{array}$ & & \\
\hline & \multicolumn{5}{|l|}{ Arrived } \\
\hline $\begin{array}{l}\text { January-August } \\
2019\end{array}$ & 7420 & 6033 & 1387 & 726757 & 734177 \\
\hline \multirow[t]{2}{*}{$\begin{array}{l}\text { January-August } \\
2018 \\
\end{array}$} & 8426 & 6561 & 1865 & 588375 & 596801 \\
\hline & \multicolumn{5}{|l|}{ Left } \\
\hline $\begin{array}{l}\text { January-August } \\
2019\end{array}$ & 31287 & 28470 & 2817 & 726757 & 758044 \\
\hline \multirow[t]{2}{*}{$\begin{array}{l}\text { January-August } \\
2018 \\
\end{array}$} & 27737 & 25191 & 2546 & 588375 & 616112 \\
\hline & \multicolumn{5}{|c|}{ Migration Balance } \\
\hline $\begin{array}{l}\text { January-August } \\
2019 \\
\end{array}$ & -23867 & -22437 & -1430 & - & -23867 \\
\hline $\begin{array}{l}\text { January-August } \\
2018\end{array}$ & -19311 & -18630 & -681 & - & -19311 \\
\hline
\end{tabular}

The statistical data of Table 1 indicate that the central migration exchange of the country occurs within The Commonwealth of Independent States (CIS) countries. The share of arrivals from $\mathrm{CIS}$ countries and departures to these countries amounted to $81.3 \%$ and $91 \%$ respectively. Analysis of statistical data shows that the number of migrants moving within the country increased by $23.5 \%$. Interregional migration of the population is presented in Figure 2.

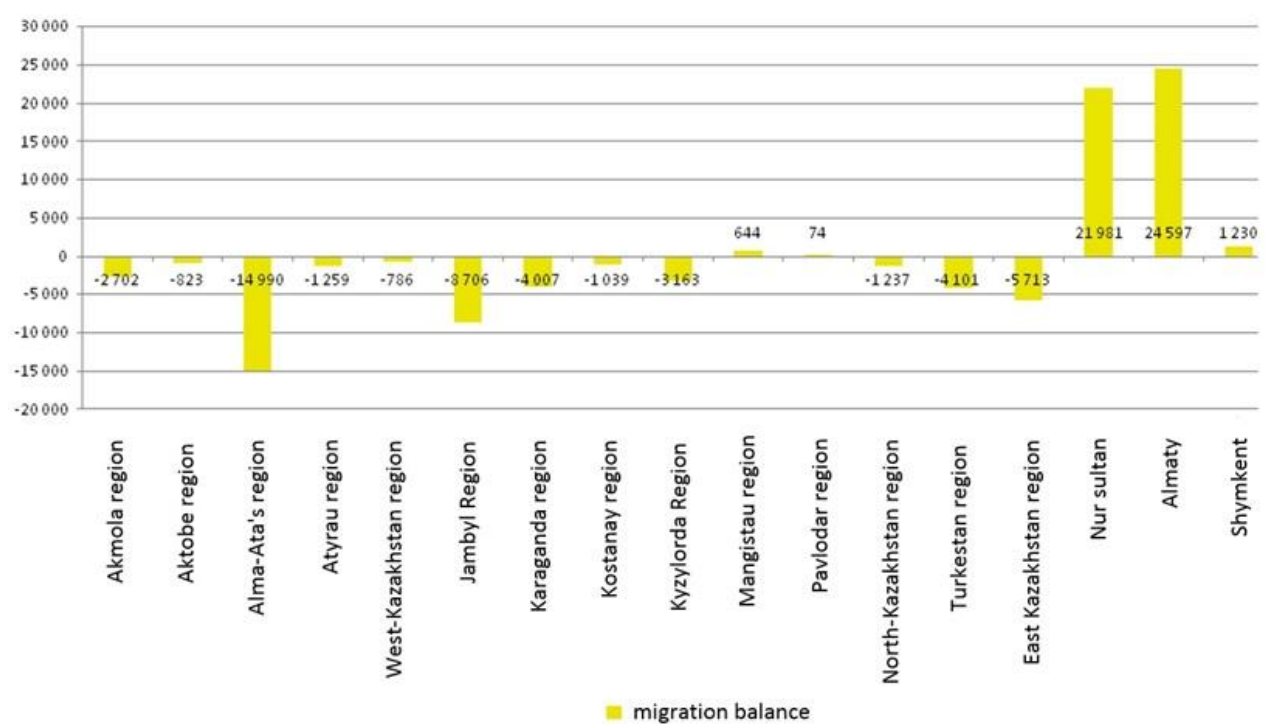

Figure 2: Interregional Population Migration for January-August 2019 (number of people) Source: Data of the Committee on Statistics of the Ministry of National Economy of the Republic of Kazakhstan (2019) 
To date, a complicated demographic situation has developed in the regions of Kazakhstan: 38\% of the population lives in the southern regions of the country. In comparison, their share in the gross regional product is only $17 \%$. In the northern regions, $29 \%$ of the population produces $25 \%$ of the gross regional product. According to forecasts, by 2050, the population of the southern regions will increase by 5.2 million people, and the population density in these regions will be almost four times higher compared to the northern regions. In other words, the forecast is indicative of the fact that the pull factors of the southern regions of Kazakhstan have more advantages for migration (Tobler, 1995). In other words, migrants are considering moving to more attractive southern regions. One can, therefore, argue that strengthened by the competitive advantages of the South of Kazakhstan have led to the emergence of push factors in other regions of the country. It should also be noted that social inequality and the search for sources to increase income have contributed not only to the uncontrolled migration flows but also to the development of informal forms of employment. For example, the regions with the highest share of informal employment include South Kazakhstan region employing $16.3 \%$ out of total informal employment. Similarly, the Almaty region employs $16.7 \%$, and Zhambyl region has employed $9.8 \%$ of the total informal employment.

Overall, these three regions cover more than $40 \%$ of the total informal employment. However, it is arguable that at present, the economic development and internal migration of Kazakhstan do not have a linear correlation (Aldashev \& Dietz, 2014). Therefore, the correct way to assess the situation is to consider labour migration in the context of economic development of both the whole republic and its individual regions, as well as to take into account the prevailing demographic trends.

According to the Committee on Statistics of the Republic of Kazakhstan (2019), the number of unemployed in Kazakhstan (as determined by the ILO methodology) in September 2019 stood at 442.2 thousand. The unemployment rate was $4.8 \%$. The employment authorities officially register 170 thousand as unemployed (the share of registered unemployed is $1.8 \%$ ). The most significant number of unemployed is concentrated precisely in the southern regions of the country:

- in the South Kazakhstan region (62.2 thousand);

- Almaty city (49.6 thousand);

- Almaty region (49.1 thousand).

The above fact once again indicates that these are labour-surplus regions. The smallest number of unemployed are in Mangistau (14.2 thousand) and North Kazakhstan region (15.2 thousand). This observation confirms the hypothesis of the existence of labour-deficient and labour-surplus regions. Currently, the problem of rural unemployment is especially relevant, since a significant part of the unemployed is among the rural population. Due to development problems in the agricultural sector, the unemployed population migrate to more populated cities, in search of employment opportunities (Bodauhan \& Jussibaliyeva, 2018b). This trend is consistent with the hypothesis of Ravenstein (1885), who stated that when a certain region becomes a "district of absorption" of internal migrants, agriculture loses a part of workers and does not acquire the status of "labour surplus" in contrast to the sectors of trade and industry.

Nevertheless, the Programme for the Development of Employment and Mass Entrepreneurship ("Enbek") for 2017-2021 has been developed and approved in Kazakhstan (hereinafter - Enbek Programme). This programme is aimed (1) at providing labour force in labour-deficient regions, and (2) at eliminating regional and demographic imbalances, etc.

The Enbek Programme is intended to become the vital instrument for regulating the labour shortage in the northern regions. The south-tonorth resettlement programme of Kazakhstan is expected to solve one of the main problems, that is, the imbalance in the population (Ministry of 
Labour and Social Protection of Population of the Republic of Kazakhstan, 2019).

The state desires to "unload" the labour-surplus southern regions and fill with labour the northern regions, thereby, providing support for the economic development of the industrial north of Kazakhstan. Following the Concept of Migration Policy, the Republic of Kazakhstan adheres to the following strategies:

- allowing temporary migration to attract foreign workers;

- optimal population distribution throughout the country;

- providing the right of return.

The Governmental policy of relocating labour resources from the southern regions to the northern regions is one of the mechanisms to resolve the demographic imbalance. It is also a response to the decrease in the number of people in four regions - Pavlodar, East Kazakhstan, Kostanay and North Kazakhstan. Kazakhstan has created a broad system of national and interstate regulation of labour migration to enhance positive effects and neutralise the negative consequences of this process.

According to the Enbek Programme, those, who have voluntarily decided to migrate from laboursurplus region to labour-deficient one are provided with the following measures of state support:

- financial assistance for resettlement;

- reimbursement of expenses for rental housing and payment of utilities;

- training, technical and vocational education and short-term professional courses, if necessary;

- assisting employment and start-ups in a new place of residence (Ministry of Labour and Social Protection of Population of the Republic of Kazakhstan, 2019).

The following are the expected results of Enbek Programme's implementation:
- The unemployment rate for the first quarter of 2019 was $4.8 \%$ (in 2021 it is expected to be no more than $4.8 \%$ ).

- The share of labour resources with basic, secondary, and primary education in the workforce, as of 01 July 2019 is $14.6 \%$. In 2021, it is expected to be no more than $20 \%$.

- The share of unproductively employed out of the self-employed population as of 01 July 2019 is 9.3\%. In n 2021 this indicator is expected to be no more than $10 \%$.

- There were 1241 thousand actively operating small and medium-sized enterprises (SMEs) as of 01 Jan 2019. The growth rate for these SMEs in the first half of 2019 was $110.3 \%$. In 2021, its growth rate is expected to increase by at least $10 \%$ (Workforce Development Centre, 2019).

Participants in Kazakhstan's resettlement programme were reportedly expecting to have a better quality of life after moving to the new place of residence (Gang \& Schmillen, 2017). These expectations largely apply to households, as about half $(47 \%)$ of the migrants were children of school and preschool age. The average age of migrants was 21.5 (Figure 3 ).

Population growth can be expected if the ratio between the working-age and retirement-age of the migrants is 98:2. Higher concentrations of migrants in northern regions will thus result in the growth and rejuvenation of the economically active population in those regions. Migration may also bring a favourable social effect.

However, the authors have determined that the mechanisms for the migration from the southern regions to the northern ones require refinement and improvement both at the regional and republican levels. Therefore, it can be stated that the measures taken to stimulate the resettlement of the population from south to north have not yet brought desired results. In 2019, the resettlement programme envisaged measures to stimulate the territorial mobility of labour resources, namely the assistance to those citizens, who decided to migrate from south to 
north. Under the Programme, in 2019 it was planned to accept in North Kazakhstan Region 690 families (3060 people) from six regions of the republic (Almaty, Zhambyl, Kyzylorda, Mangistau and Turkestan regions and the city of Shymkent).
Figures $4 a$ and $4 b$ show data on the number of families that have migrated to the North Kazakhstan Region from other regions of Kazakhstan in 2019.

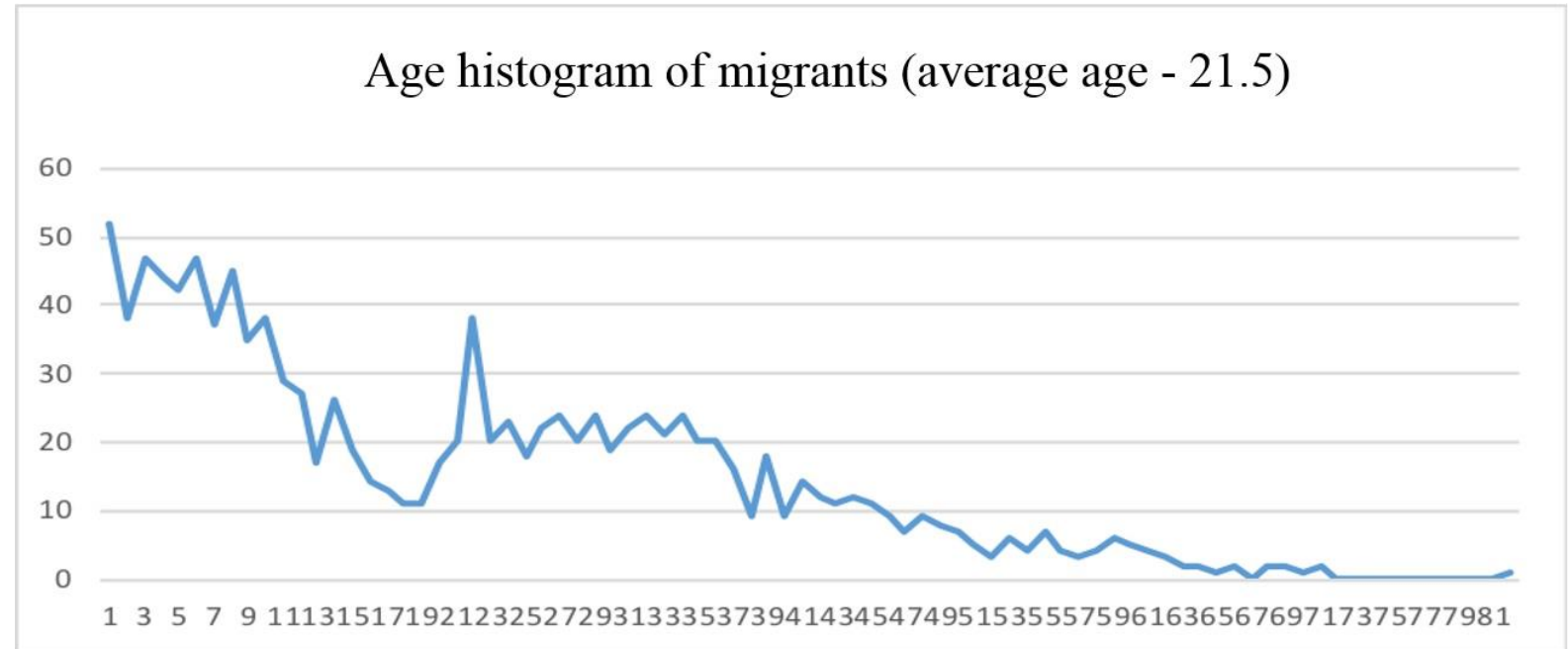

Figure 3: Age Histogram of Migrants

Source: Developed on the Basis of Data from the Department for Coordination of Employment and Social Programmes (2019).

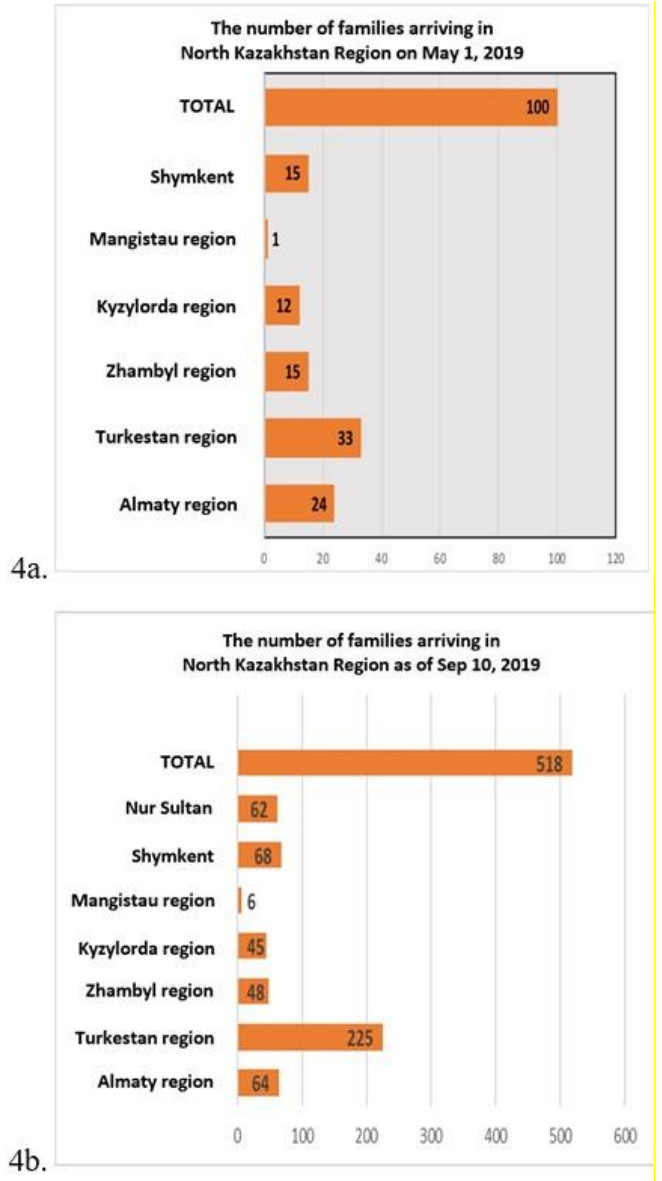

Figure 4: The Number of Families Migrating to the North Kazakhstan Region from other regions of Kazakhstan as of 01 May (4a) and 10 September 2019 (4b) Source: Developed on the basis of data from the Department for Coordination of Employment and Social Programmes of the North Kazakhstan Region (2019) 
Judging by the data on the number of families arriving in the North Kazakhstan Region as of 01 May, 2019, as shown in Figures $4 a$ and $4 b$, it can be seen that more families have migrated from the Turkestan region. As for 2017, the majority of migrants arrived from the South Kazakhstan region (47\%), from Almaty and Zhambyl regions, the percentage of migrants stands at $21 \%$ each. In 2018, there were $42 \%$ of migrants from the South Kazakhstan region, 28\% from Zhambyl region and $14 \%$ from Almaty region. Similarly, in
2019 , the percentage of migrants from South Kazakhstan region stood at $43.4 \%$ followed by Shymkent $-13.1 \%$, Almaty region $-12.4 \%$, NurSultan $-12 \%$, Zhambyl region $-9.2 \%$, and Kyzylorda region - 8.7\% (Department for Coordination of Employment and Social Programmes of the North Kazakhstan Region, 2019). Figure 5 (that is, $5 a$ and $5 b$ ) shows the demographic composition of migrants in the North Kazakhstan region.

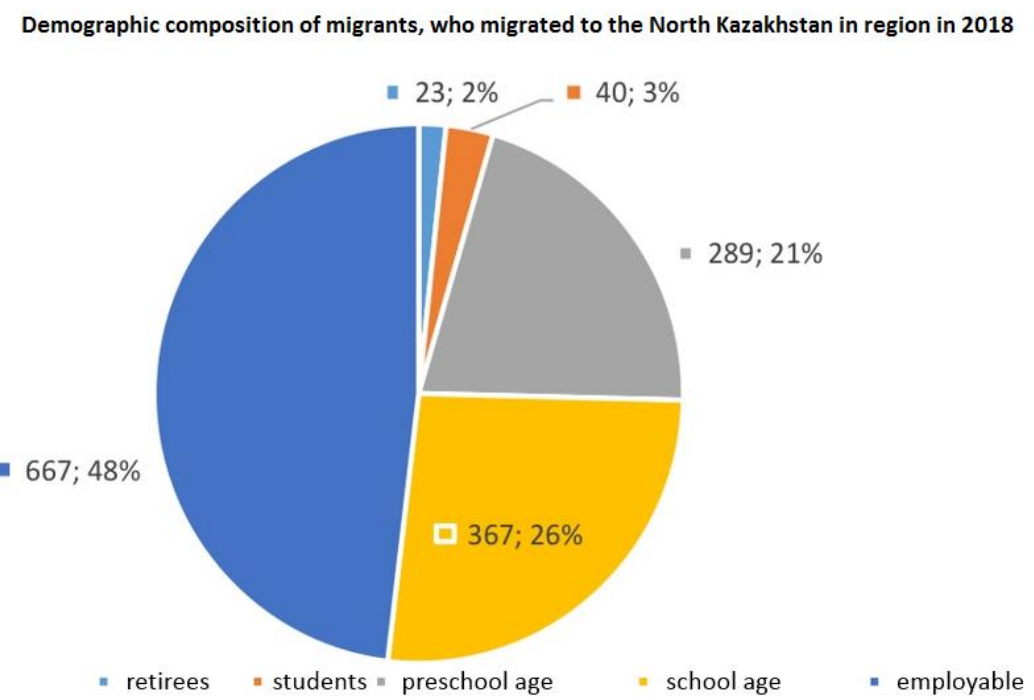

Demographic composition of migrants, who migrated to the North Kazakhstan region in 2019 | employable || children || students | retirees

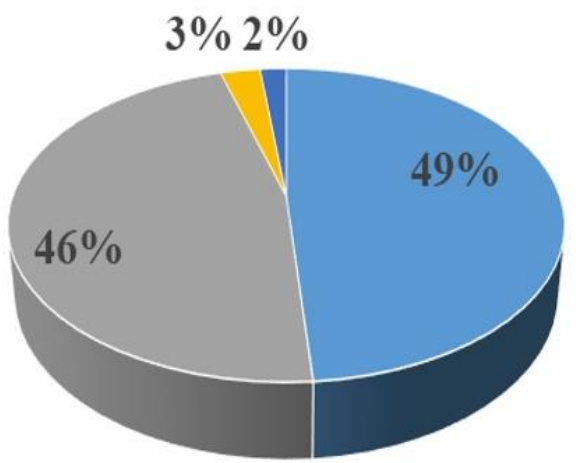

Figure 5: The Demographic Composition of Migrants (5a. 2018; 5b. in 2019) Source: Developed on the Basis of Data from the Department for Coordination of Employment and Social Programmes of the North Kazakhstan Region (2019).

Out of the employable migrants, more than $30 \%$ do not have specialised education, and, therefore, difficulties arise with their employment. In the authors' opinion, the issues of employment and placement of migrants still need to be resolved. According to analytical data, it was determined that $48.7 \%$ of all migrants are employable. Out of this figure, $28 \%$ is employable in higher education, $41 \%$ in 
specialised education and $31 \%$ in secondary education.

The results of the study show that there is a low degree of public awareness in the regions concerning opportunities for internal migration. Some of this unawareness is:

- persons with a priority right to relocate;

- subsidies allocated by the state;

- measures of state support, including social assistance for migrants, etc.

In general, low public awareness harms the effectiveness and productivity of the Resettlement Programme (Bodauhan, Jussibaliyeva, \& Bolatova, 2019a).

In the authors' opinion, it is essential to identify external and internal migration issues as well as the most problematic regions.

\section{Discussion}

This study set out with the aim of assessing migration processes and recommendations on the regulation of internal migration from Southern to Northern regions of Kazakhstan. To improve the regulation of migration from labour-surplus southern regions to labourdeficient northern regions of Kazakhstan, the following alternatives may be considered:

1. For the practical solution of problems arising in the process of resettlement, it is necessary to create a specialised centre (service) at the level of local executive authorities (Nikolova \& Graham, 2015). The main functions of such a centre will be as follows:

- constant monitoring of migrants and their families regarding their resettlement, normal housing conditions;

- providing social and other infrastructure (kindergartens, schools, medical services, etc.);

- assistance in solving the problems of employment;

- assistance in social and labour adaptation;

- raising public awareness concerning state support measures;
- collection and analysis of information on the number of people who have moved to labour-deficit regions, the number of people employed in a particular field of activity;

- assistance in solving social, labour, legal and other issues that arise in the process of migrant's adaptation;

- strengthening regional and social infrastructure, creating conditions to improve the living standards of the population.

2. There is a need to develop and implement an appropriate state or regional programme for the relocation of the population from labour-surplus to labour-deficient regions of Kazakhstan. Such a programme will be aimed specifically at addressing the issues of internal migration of the population from labour-surplus (southern) to labour-deficient (northern) regions of the country. The need for the programme is due to the following:

- firstly, the lack of a particular programme for the resettlement of the population in Kazakhstan. The existing Enbek Employment Programme only partly covers this issue;

- secondly, the existing programmes do not solve the whole range of tasks and problems that arise during the resettlement;

- thirdly, the direction of the Bastau Business Programme does not adequately address the issues of entrepreneurship development, especially in the field of agriculture, in which migrants could work productively (Ryazantsev, Khramova, \& Delovarova, 2018).

The Bastau Business Program is designed to provide the basic knowledge of entrepreneurship and marketing to the rural population to shape an entrepreneurial mindset among rural residents and to facilitate the acquisition of business skills by participants that are needed to successfully perform in new market conditions (Bastau Training Program, 2016). 
It is relevant to develop and implement a new programme that will deal with the problem of attracting additional labour resources to the labour-deficient regions.

3. There is a need to introduce a unified automated information system of data on migrants on the principle of "one window" for conducting extensive monitoring and accounting of:

- directions and places of resettlement;

- obtaining measures of state support;

- employment;

- professional competencies;

- housing;

- social infrastructure, etc.

There are automated information systems "Foreign workforce", "Migration Police "Berkut", integrated with information systems of public bodies. A new integrated migration system should include information about employers, vacant jobs, conditions of employment so that migrants can get the necessary information. This will help ensure that the expectations of the migrants correspond to the interests of the employers and the real opportunities of the labour market of the region.

4. Additional incentive measures are to be implemented for voluntary resettlement of Kazakhstan citizens to regions with a shortage of labour. The authors propose some of the support measures:

- development of agriculture companies;

- support of small and medium-sized businesses in agriculture;

- development of agri-business;

- processing of livestock;

- other activities where migrants can be productively employed.

5. A specific mechanism is needed for providing housing for migrants. Employers themselves (farms, organisations, companies) are to be involved in solving this issue. One of the implementation tools can be the provision of land, as well as concessional lending for the construction of migrants' own housing, especially for those migrants, who want to live close to each other. For example, because of kinship, friendship, or for the purpose of joint small business in agriculture, etc. (Girkar, Jaiswal, Nigam, \& Arora, 2019). The solution of this issue must be carried out, taking into account the real potential of the region in terms of employment, development of small and medium-sized enterprises.

6. Centres are to be created for adaptation and integration of migrants from South Kazakhstan in the North Kazakhstan, Pavlodar, East Kazakhstan and Kostanay regions. It is advisable to assess the degree of influence of attractive, objective and subjective factors. Such an assessment will become the basis for modelling the complex of pull-factors (Tobler, 1995), that will stimulate the natural (that is, not artificially created) flow of internal migrants to the North of Kazakhstan.

7. Dynamics of population reproduction should be monitored as it affects the quantity and quality of the migration potential. Such monitoring should be considered as an indirect assessment of the quality of life in regions and the country as a whole (Fierman, 2019). A necessary component of the analysis of reproductive processes is the assessment of the age and sex composition of the population.

8. Both central and local executive bodies should address the issues of employment and wages of migrants. It is necessary to attract employers (the private sector) as much as possible to ensure the productive employment of migrants. To resolve this issue, a precise operating mechanism is needed. Local executive bodies need to actively involve the entrepreneurial and industrial sectors as well as agribusiness of the region to ensure the productive employment of migrants. At the same time, the proposed socioeconomic measures should be implemented along with permanent monitoring of indicators of social welfare in order to prevent macroeconomic structural asymmetries and the reverse migration flow, as stated in the 7th Law from the Laws of Migration (Ravenstein, 1885).

As the authors noted above, one of the main tasks of the state is to ensure conditions for an even distribution of labour resources. The most pressing issue in the northern regions of 
Kazakhstan is the shortage of labour and unqualified personnel, while the southern regions are labour-surplus (Bodauhan, Jussibaliyeva, \& Kochyigit, 2019b). In this regard, resettlement programmes should include the following aspects:

- Forming a system for monitoring the resettlement processes (Roche, 2018).

- Creation by the state of all necessary legal, socio-economic, organisational and informational conditions conducive to voluntary resettlement to labourdeficient regions for permanent residence and employment (Adams, 2018).

- The provision of full and necessary assistance to migrants in matters of their housing, social and cultural adaptation at all stages of resettlement (Geddes, Espinoza, Abdou, \& Brumat, 2019).

- Persuading talented youth (among the migrants) to get an education in educational institutions and organisations located in the region of migration.

\section{Conclusion}

The resettlement programme is of great macroeconomic importance for Kazakhstan; it is long-term and implies that migrants in the future will positively contribute to natural population growth. Voluntary resettlement of labour resources is designed to fill vacancies in critical sectors of the economy, especially in the agricultural sector of Kazakhstan.

The industrial significance of the resettlement is explained by the fact that the country's labourdeficient regions will be provided with qualified personnel. The latter will contribute to the following:

- fulfilment of the country's strategic economic goals and objectives;

- innovative achievements;

- technological modernisation;

- implementation of new industrial programmes and investment projects.

The greatest outflow of the population is seen in those areas where the development of many forms of farming has completely or partially stopped (that have also led to unemployment). It is revealed that there is a close relationship between migration and the outflow of labour. State incentives for productive employment are a priority area of partial prevention of regional migration imbalance and urbanisation. Besides, demographic processes and changes in the ratio of working-age people and retirees have a strong influence on structural changes in the national economic system.

Despite the presence of laborious studies on migration issues in Kazakhstan, issues of internal migration from labour-surplus to labourdeficient regions of Kazakhstan are not sufficiently studied, especially through the prism of values, motives, mental and cultural characteristics of migrants. Besides, the influence of migration processes on the development of the national economy as a whole and, in particular, the agricultural sector remains unexplored, which determines a further vector of research.

\section{References}

Adams, O. Y. (2018). Migration in Kazakhstan after 1991: Official Responses to Trends and Contentions. Journal of Tzu Chi University of Science and Technology, 7, 71-113.

Aldashev, A, \& Dietz, B (2014). Economic and spatial determinants of interregional migration in Kazakhstan. Economic Systems, 38, 379-396. https://doi.org/10.1016/j.ecosys.2013.10. 004

Bastau Training Program (2016). Retrieved from: https://atameken.kz/ru/pages/833metodika

Bodauhan, K., \& Jussibaliyeva, A. K. (2018a). The main aspects of state regulation of migration processes in the Republic of Kazakhstan. Economics and Statistics, 2, 113-123.

Bodauhan, K., \& Jussibaliyeva, A. K. (2018b). The impact of migration processes on employment in agriculture of the Republic 
of Kazakhstan. Problems of the Agricultural Market, 1, 171-178.

Bodauhan, K., Jussibaliyeva, A. K., \& Bolatova, B Zh. (2019a). Problems of internal migrations and employment in the agrarian sector of Kazakhstan. Problems of the Agricultural Market, 1, 171-180.

Bodauhan, K., Jussibaliyeva, A. K., \& Kochyigit, Zh. (2019b). Recommendations on the regulation of migration and resettlement of the population from southern to northern regions of Kazakhstan (based on materials from the North Kazakhstan region). Astana: Profi-Media.

Committee on Statistics of the Ministry of National Economy of the Republic of Kazakhstan (2019). Retrieved from: http://stat.gov.kz

Department for Coordination of Employment and Social Programs of the North Kazakhstan Region (2019). Retrieved from: http://ukzsp.sko.gov.kz/

Fierman, W. (2019). Soviet Central Asia: the failed transformation. Routledge.

Gang, I. N., \& Schmillen, A. (2017). Sometimes, winners lose: Economic disparity and indigenization in Kazakhstan. Journal of Comparative Economics, 45(3), 605-621. https://doi.org/10.1016/j.jce.2016.11.002

Geddes, A., Espinoza, M. V., Abdou, L. H., \& Brumat, L. (2019). The Dynamics of Regional Migration Governance. Edward Elgar Publishing.

Girkar, U., Jaiswal, P., Nigam, A., \& Arora, T. (2019). Understand the effect of environmental and structural migration factors on the sexual and reproductive health of youth in central Asia and Africa: a modelling study. The Lancet Planetary Health, 3, S3. https://doi.org/10.1016/S25425196(19)30146-9

Ministry of Labour and Social Protection of Population of the Republic of Kazakhstan (2019). The concept of migration policy of the Republic of Kazakhstan for 2017-2021. Retrieved from: www.enbek.gov.kz

Nikolova, M., \& Graham, C. (2015). In transit:

The well-being of migrants from transition and post-transition countries. Journal of Economic Behavior \& Organization, 112, 164-186.

https://doi.org/10.1016/j.jebo.2015.02.00 3

Ravenstein, E. G. (1885). The Laws of Migration. Journal of the Statistical Society of London, 48(2), 167-235. https://doi.org/10.2307/2979181

Roche, S. (2018). Status translation: Central Asian migrants between ethnic discrimination and religious integration. Anthropological Journal of European Cultures, 27(1), 94-98. https://doi.org/10.3167/ajec.2018.27011 4

Ryazantsev, S. V., Khramova, M. N., \& Delovarova, L. F. (2018). Kazakhstan as a Migration Hub of Eurasia: Contribution of Migration to Sustainable Development. Retrieved from: http://www.isprras.ru/pics/File/2018/Info rmLetter_Kazakhstan_160ct2018_engl.pd $f$

Shakhaman, Z., Taskuzhina, A., \& Kudritskaya, M. (2018). International Migration (19912017) and Environment: Experience of Kazakhstan. In Integration of the Scientific Community to the Global Challenges of Our Time (pp. 14-22). Materials of the III International Scientific-Practical Conference. Pavlodar: Public Fund "Regional Academy of Management".

Tobler, W. (1995). Migration: Ravenstein, Thornthwaite and Beyond. Urban Geography, 16(4), 327-343. https://doi.org/10.2747/02723638.16.4.327

Workforce Development Centre (2019). Retrieved from: http://iac.enbek.kz 


\section{Author Contribution Statement}

Kairat Bodaukhan and Aruzhan Jussibaliyeva: conceptualisation, methodology, and software contribution; Raushan Mussina: curation of data, developing the first draft; Darima Zhenskhan, Indira Amerkhanova and Zhanerke Kochiigit: Conducting empirical research and visualisation of data; Darima Zhenskhan and Zhanerke Kochiigit: Guidance and Supervision; Kairat Bodaukhan and Aruzhan Jussibaliyeva: contribution in software and validation of data; Raushan Mussina and Indira Amerkhanova: developing the final draft alongside editing and reviewing. All authors have read and agreed to the published version of the manuscript. 